\title{
Inflammation Mediators Related to Periodontal Disease and Pregnancy Outcomes: A Call for Quality of Antenatal Care While Promising Evidences Are Emerging
}

\author{
Juliana P. S. Faquim ${ }^{1}$, Ana Paula de L. Oliveira ${ }^{2}$, Marcelo J. B. Silva ${ }^{3} \&$ Paulo Frazão ${ }^{4}$ \\ ${ }^{1}$ Technical School of Health, Federal University of Uberlândia, Brazil \\ ${ }^{2}$ Dental School, Federal University of Uberlândia, Brazil \\ ${ }^{3}$ Institute of Biomedical Sciences, Federal University of Uberlândia, Brazil \\ ${ }^{4}$ Department of Policy, Management and Health, Public Health School, University of São Paulo, Brazil \\ Correspondence: Prof. PhD. Juliana P. S. Faquim, Technical School of Health, Federal University of Uberlândia, \\ Ave Amazonas, Bl 4k-136 Uberlândia-MG, Brazil. Tel: 55-34-3225-8462.
}

Received: October 27, 2016 Accepted: July 18, 2017 Online Published: July 31, 2017

doi:10.5539/gjhs.v9n8p169 URL: https://doi.org/10.5539/gjhs.v9n8p169

\begin{abstract}
Infections may play a significant role in the induction of births and prematurity. Periodontal disease could be a risk factor for pregnancy outcomes such as preterm birth, and low birth weight. Possible mechanisms of this relationship are the production of inflammatory mediators and cytokines like C-reactive protein (CRP), prostaglandin E2 (PGE2), matrix metalloproteinases, interleukin 1 (IL-1), IL-6, and tumor necrosis factor alfa (TNF-a); the translocation of periodontal pathogens to the feto-placental unit through blood stream, a periodontal reservoir of lipopolysaccharides (LPS); and shared risk factors. Although this knowledge is just emerging, it has important implications for the health services and the healthcare delivery model. Committed health teams to an interprofessional collaborative work within the health services can raise the quality of antenatal care. Population strategies directed to prevent and control periodontal disease can increase the periodontal health of the majority of people and affect positively risk groups. These inexpensive basic measures joined with other actions at different levels could enhance the quality of antenatal care and contribute for favorable pregnancy outcomes. Further researches need to clarify the evidences on those relationships.
\end{abstract}

Keywords: periodontal diseases, infections, pregnancy, inflammation mediators, public health

\section{Introduction}

Preterm birth is defined as babies born alive before 37 weeks of pregnancy are completed. The preterm subcategories, based on gestational age are: extremely preterm ( $<28$ weeks), very preterm ( 28 to $<32$ weeks), moderate to late preterm ( 32 to $<37$ weeks). This usually causes low birth weight babies, which most studies considered a reference value of $<2,500 \mathrm{~g}$. It remains an important and major cause of perinatal mortality and morbidity throughout the world, and its rate is increasing worldwide (Zi, Longo, Bueno-Silva \& Mayer, 2013).

The etiology is considered multifactorial and events that lead to preterm birth are not yet fully understood. It is not easy to understand whether premature birth results from the interaction of several causal routes or the independent effect of each route. The reasons that can lead to prematurity may be related to medical conditions of the mother or fetus, increases in maternal age, underlying maternal health problems such as diabetes and high blood pressure, genetic influences, environmental exposure, infertility treatments leading to increased rates of multiple pregnancies, behavioral and socioeconomic factors, iatrogenic prematurity and changes in obstetric practices such as more caesarean births before term (Goldenberg, Culhane, Iams, \& Romero, 2008; WHO, 2016).

Risk factors for preterm birth and low birth weight include maternal age $(<17$ and $>34$ years), higher rates of teenage pregnancy, chronic maternal malnutrition, low weight gain in pregnancy, low maternal height, low pre-pregnancy body-mass index, African American ancestry, low socioeconomic status, multiple pregnancies, smoking, alcohol, drug abuse. Chronic conditions such as diabetes and high blood pressure have also been considered a risk factor for preterm birth (Katz et al., 2013; Kawar \& Alrayyes, 2011). The most relevant risk factor among all is the infection status. Infections during pregnancy caused by bacteria, viruses, and parasites may 
be associated with preterm birth and also with fetal malformation depending on the pathogen (Katz et al., 2013; Kawar \& Alrayyes, 2011).

Infections in other parts of the body may also play an important role in the induction of births and prematurity by favoring an immune response joined to the transit of microorganisms and/or their toxins in the bloodstream to the maternal-fetal unit (Uppal et al., 2010). In this matter, many adverse pregnancy outcomes such as pre-term delivery and preterm low birth weight infants may be associated to the infected periodontal tissues (Offenbacher et al., 2001).

\section{Epidemiologic Data Concerning Preterm Birth}

Although over $60 \%$ of preterm births take place in Africa and South Asia, preterm births are considered a global problem ( $\mathrm{Zi}$ et al., 2013). The rate of preterm birth ranges from 5 to $18 \%$ of the babies born all over the world. It ranges from $8 \%$ in Canada to $12 \%$ in the USA. In Latin America, preterm births comprise $14 \%$ of live births in Costa Rica while 7\% in Chile and 9\% in Brazil. In Europe, it reaches 15\% in Cyprus, $6 \%$ in Scandinavian countries, $7-9 \%$ in France, Italy, and Germany and UK. In Asia, the rate is 7\% of live births in China (WHO, 2016).

The ten countries with the highest number of preterm births are India (3.519.100), China (1.172.300), Nigeria (773.600), Pakistan (748.100), Indonesia (675.700), The United States of America (517.400), Bangladesh (424.100), The Philippines (348.900), The Democratic Republic of the Congo (341.400) and Brazil (279.300) (Blencowe et al., 2012).

About 15 million babies are estimated to born too early every year. That is more than 1 in 10 babies. Almost 1 million children die each year due to complications of preterm birth. Many survivors face a lifetime of disability, including learning disabilities and visual and hearing problems. Globally, prematurity is the leading cause of death in children under the age of five. Moreover, preterm birth rates are increasing in almost all countries with reliable data (WHO, 2016).

Differences in survival rates around the world are severe. While in high-income countries, almost all of these babies born at 32 weeks (two months early) survive, in low-income settings, half of the babies die due to a lack of feasible, cost-effective care, such as warmth, breastfeeding support, and basic care for infections and breathing difficulties (WHO, 2016).

Out of all early neonatal deaths (within the first 7 days of life) that are not related to congenital malformations, $28 \%$ are due to preterm birth (Lawn, Wilczynska-Ketende, \& Cousens, 2006). Preterm birth rates have been reported to range from $5 \%$ to $7 \%$ of live births in some developed countries, but are estimated to be substantially higher in developing countries (Lawn et al., 2006). These figures appear to be on the rise (Goldenberg et al., 2008).

Preterm birth has profound economic consequences. After discharge from hospital, the greatest costs associated with prematurity lie not in health care but in education (Petrou, Abangma, Johnson, Wolke, \& Marlow, 2008). Compared with term-born peers, children born very preterm $(28<32$ weeks' gestation) are at increased risk for neurodevelopmental sequel, such as cerebral palsy, vision, and hearing impairments (Saigal \& Doyle, 2008). However, cognitive and behavioural problems (particularly inattention), peer relationship problems, and deficits in executive functions, are far more prevalent and account for most functional disability in this population.

\section{Periodontal Disease as a Potential Risk Factor for Adverse Pregnancy Outcomes}

Periodontal disease is a chronic inflammatory disease of the soft and hard tissues that support the teeth, caused by bacterial plaque and influenced by host response factors (Zi et al., 2013; Takeuchi et al., 2013; Muwazi et al., 2013). There are two main types of conditions; gingivitis and periodontitis. While gingivitis is an inflammation of soft tissues surrounding the tooth, periodontitis involves apical migration of the periodontal ligament attachment and destruction of the connective tissue and alveolar bone that support the teeth (Pihlstrom, Michalowicz, \& Johnson, 2005; Tonetti et al., 2007). Periodontitis can affect most teeth, or can be limited to a group of teeth, respectively generalized and localized forms ( $\mathrm{Zi}$ et al., 2013). It is usually divided into chronic and aggressive periodontitis (Armitage, 1999). Chronic periodontitis is characterized by a slow and continuous destruction of periodontal tissues (Darveau, 2010; Kolenbrander, Palmer, Periasamy, \& Jakubovics, 2010), while the loss of the periodontal ligament and alveolar bone is more fast and severe in aggressive periodontitis (Nibali, Farias, Vajgel, Tu, \& Donos, 2013).

Some of the important clinical features include erythema of the gingiva, edema, hyperplasia, increased bleeding, alterations in the gingival color, tooth mobility, dental migration, pocket depth (Muwazi et al., 2013; Michalowicz et al., 2008).

During pregnancy, gingivitis is one of the most common conditions, affecting $60 \%$ to $75 \%$ of all pregnant women 
(Michalowicz et al., 2008). It is characterized by erythema of the gingiva, edema, hyperplasia, and increased bleeding (Sooriyamoorthy \& Gower, 1989; Ferris, 1993). Pregnancy gingivitis affects $36-100 \%$ of pregnant women (Carrillo-de-Albornoz, Figuero, Herrera, \& Bascones-Martínez, 2010) and the prevalence and severity of gingivitis increase throughout the gestational period. The gingival inflammatory changes are generally observed in the second or third month of pregnancy, persist or increase during the second trimester, and then decrease in the last month of pregnancy, eventually regressing after parturition (Ferris, 1993; Amar \& Chung, 1994). This increase in inflammatory signs is disproportionate to the quantity of plaque accumulation (Loe, Theilade, \& Jensen, 1964; Cohen, Friedman, Shapiro, \& Kyle, 1969).

The underlying mechanism for this enhanced inflammatory response during pregnancy is the elevated level of progesterone and estrogen, amplifying the gingival inflammation (Zachariasen, 1992; Raber-Durlacher, Leene, Palmer-Bouva, Raber \&Abraham-Inpijn, 1993). The severity of the response is directly attributed to the levels of these hormones (Steinberg, Hilton, Iida, Iada, \& Samelson, 2013) and associated to increased vascular permeability, decline of the immune system, and changes on the composition of supra and subgingival microbiota (Carrillo-de-Albornoz et al., 2010).

Some studies have suggested that periodontal disease could be a risk factor for pregnancy outcomes such as preterm birth, and low birth weight deliveries and premature rupture of membranes due to its inflammatory and infectious nature (Offenbacher et al. 2001; Ainamo \& Bay, 1975). Possible mechanisms of this relationship are production of inflammatory mediators, translocation of periodontal pathogens to the feto-placental unit through blood stream, a periodontal reservoir of lipopolysaccharides (LPS), and shared risk factors (Offenbacher et al., 1998).

Recent evidence supports periodontal disease as an oral inflammatory disease caused by gram-negative anaerobic bacteria related to the onset of labor (Macedo et al., 2014). The disease activity increases the host inflammatory mediators and cytokines like C-reactive protein (CRP), prostaglandin E2 (PGE2), matrix metalloproteinases, interleukin 1 (IL-1), IL-6, and tumor necrosis factor alfa (TNF-a) (Lin et al., 2003). As a result, these mediators can trigger early parturition (Davenport et al., 1998; Offenbacher, 2004; Thousand, 2012). In women that have periodontitis, TNF-a and IL-6 levels were higher compared to the group that do not have disease (Sert, Kirzioglu, Fentoglu, Aylak, \& Mungan, 2011). Additionally, the imbalance between anti-inflammatory cytokines, such as IL-10 and proinflammatory cytokines, such as IL-1b, may also contribute to the feto-placental process (Keelan et al. 2003) and periodontal disease (Lima Oliveira et al., 2012).

Bacterial lipopolysaccharide (LPS) stimulates the production of inflammatory cytokines and inflammation mediators, including arachidonic acid and metabolites like PGE2 (Huck, Tenenbaum, \& Davideau, 2010). Current understanding of the biological events surrounding normal labor and preterm labor strongly suggests that prostaglandins play a pivotal role in the initiation process (Tarannum, Faizuddin, \& Madaiah, 2011). Some reports have suggested that periodontal infections, which serve as a reservoir of inflammatory mediators such as PGE2, may pose a threat to the fetal-placental unit. Offenbacher et al. (1998) analyzed the relationship between PGE2 level in the gingival crevicular fluid (GCF) and delivery outcomes and demonstrated that several periodontal pathogens as well as PGE2 were found in higher levels in women with preterm delivery. Tarannum et al. (2011) showed that the mean serum PGE2 level was higher in mothers of preterm birth infants than in mothers of full-term birth infants, and was also higher in mothers of low-birth-weight infants than in mothers of normal-birth-weight infants. Their results also showed that the mean level of PGE2 in GCF was higher in mothers of low-birth-weight infants than in mothers of normal-birth-weight infants, and was higher in mothers of preterm birth infants than in mothers of full-term birth infants.

Studies of cytokine levels in GCF have suggested that TNF- $\alpha$ levels are lower in periodontally healthy subjects than in subjects with advanced periodontitis, who have higher levels of TNF- $\alpha$ in GCF both at sites with or without evidence of disease (Bastos et al., 2008; Kumar et al., 2014). TNF-a promotes structural and functional changes in endothelial cells including oxidative stress, activation of the complement cascade, secretion of vasoconstrictors, microthrombosis and infarction, and elevated thromboxane levels, that so is observed in pre-eclampsia (Anim-Nyame et al., 2003). Women with periodontal disease that developed pre-eclampsia have higher levels of TNF-a compared with women with no periodontal disease but that developed pre-eclampsia (Kumar et al., 2014). Not only inflammatory but also anti-inflammatory cytokines are involved with adverse pregnancy outcome. IL-4 and IL-10 are related to unfavorable pregnancy outcomes (Kramer et al., 2009).

Furthermore Offenbacher et al. (2005) reported that an increased risk of preterm or low birth weight would be related to the progression of periodontal disease during pregnancy or to the prior existence of severe periodontal lesions. These findings corroborated the results of other clinical and laboratorial studies (Jeffcoat et al., 2001; 
Madianos et al., 2001) suggested that patients with severe and generalized periodontal disease or progressive disease during pregnancy would be more susceptible to develop adverse pregnancy outcomes. Available data show that maternal periodontitis is modestly but significantly associated with preterm birth, low birth weight and preeclampsia. However maternal periodontal therapy provided during gestation have not improved significantly the pregnancy outcomes and further longitudinal, epidemiological and interventional studies are needed (Papapanou, 2015).

During pregnancy, due to hormonal changes, there is an increase in vascular permeability that facilitates the entry of periodontal pathogens and their products into the bloodstream and into the placenta. The inflammatory process associated with periodontal disease may contribute to the transport of oral microorganisms to the circulation. Once inside the bloodstream and due of the slow blood flow in the placental venous sinuses and the invading properties of the bacteria, the pathogens have the opportunity to invade the endothelial cells lining the vessels, cross the endothelium, proliferate in the surrounding tissues and finally spread to the fetal systemic circulation and amniotic fluid. The presence of bacteria and their products in the placenta and the fetal compartment stimulates a fetal immune response characterized by the production of IgM antibodies against the pathogens and the secretion of elevated levels of pro-inflammatory cytokines (Madianos, Bobetsis, \& Offenbacher, 2013).

Moreover, infection and inflammation in the placenta will down-regulate the expression of genes related to growth and development of the placenta and the fetus contributing to a significant alteration in the architecture of the placenta, especially in areas that are critical for the exchange of nutrients between the mother and the fetus (Kumar et al., 2014). Impaired nutrient transportation via the placenta may lead to low birth weight, while structural damage of the blood vessel-rich placenta may disrupt normal blood flow and increase maternal blood pressure initiating pre-eclampsia (Madianos et al., 2013).

\section{A Call for Action While Promising Evidences Are Just Emerging}

Although the above knowledge needs more support from further researches it has important implications for the health services and the healthcare delivery model. The connections between oral health and systemic health are increasingly clearer at the individual level. The body of evidence that periodontal disease is associated with negative systemic health consequences for individuals with certain conditions and diseases is remarkable (Mawardi, Elbadawi, \& Sonis, 2015). A crucial implication from this refers to the health services and the healthcare delivery model that are put in operation. The chronic disease management cannot disregard the periodontal treatment as part of the health care when aiming at reaching an optimal level of quality compatible with current evidences (Schwab et al., 2014). In the antenatal care, recent guidelines have highlighted the importance of a comprehensive healthcare provision for the pregnant women standing out oral healthcare. In order to enhance the quality of antenatal care and contribute to the reduction of the high rates of mother and newborn mortality and morbidity, some countries have developed protocols paying attention to the health of pregnant women to include dental care during prenatal exams. In 2012, a new consolidated set of guidelines, Pregnancy: A National Consensus Statement, co-sponsored by both the American Congress of Obstetricians and Gynecologist and the American Dental Association, reinforced the importance of women receiving oral health education, oral healhcare, management and treatment during pregnancy (Vamos et al., 2014).

These new recommendations challenge the health services, particularly their traditional structures and work processes directed to the health care (Steinberg et al., 2013).

In general, health services do not work collaboratively and health authorities have failed to assure a political environment that enhance the sector's response capacity. According to the WHO (2008), a disproportionate focus on specialist, fragmentation and the diffusive commercialization of health care persist as important threats maintaining unregulated health systems (WHO, 2008). Thus, health professionals usually do not provide oral healthcare to pregnant women that in turn do not seek this modality of care. The result is oral healthcare is not viewed as a relevant component of a healthy pregnancy. That is the reason why it is important to implement and maintain oral health on the public policy agenda in the coming years ensuring conditions for committing health teams to an interprofessional collaborative work (Frazão, 2009). As the pregnancy affects mainly gingiva condition, dental hygienists have significant role in primary health teams (Kloetzel, Huebner, Milgrom, Littell, \& Eggertsson, 2012).

At population level, periodontal disease should be viewed as a public health problem. It is widespread; the social, psychological and economic consequences impact severely individuals, communities and health services, causing tooth loss, disability, masticatory dysfunction, and poor nutritional status. Moreover, the costs to society are considerable and effective methods are available to prevent and control it (Batchelor, 2014). In an editorial at British Medical Journal, professor Chapple states that it is "time to take periodontitis seriously" (Chapple, 2014). 
Current evidences support that periodontal disease and non-communicable chronic diseases share common risk factors such as tobacco use, excessive alcohol consumption, stress, malnutrition and poor hygiene practices. People who consume tobacco are more likely to drink alcohol and to eat an unhealthy diet, poor in fiber and polyunsaturated fatty acids and rich in fats and sugars (Petersen \& Ogawa, 2005). Therefore, population strategies directed to prevent and control periodontal disease should be integrated with strategies directed to prevent and control non-communicable chronic diseases. These strategies should use the acknowledged health promotion mechanisms and principles of surveillance for measuring the progress.

Specialists have postulated an approach based on three strategies: a population strategy for changing life practices, specifically those related to smoking behavior and oral self-care (plaque removal) in the community; a strategy to detect and treat people with destructive periodontal disease; and a high-risk strategy for treating existing disease and preventing further disease in those at special risk (Thomson, Sheiham, \& Spencer, 2012).

Moreover, any whole population strategy to prevent periodontal disease should consider that oral hygiene behavior is part of general cleanliness and that oral hygiene methods should be socially acceptable and easily incorporated into daily activities. According to the characteristics of the population, tailored programs should be designed to assure information and affordable toothbrushes and dentifrices. A small reduction overall of dental bacterial plaque per year through a population-based strategy can increase the periodontal health of the majority of people and affect positively risk groups. Women in general and pregnants in particular could be mainly benefitted considering their hormonal changes. These inexpensive basic measures joined with other actions at different levels could enhance the quality of antenatal care and contribute for the reduction of low weight at birth rates and premature births, while more researches are structured to clarify the evidences on those relationships.

\section{Conclusions}

Infections may play an important role in the induction of births and prematurity and periodontal disease may be a risk factor for adverse pregnancy outcomes. The implication for the healthcare delivery model is that health teams should be committed to an interprofessional collaborative work within the health services seeking to raise the quality of antenatal care. Population strategies directed to prevent and control periodontal disease should be implemented to increase the periodontal health of the majority of people and affect positively risk groups. Inexpensive basic measures joined with other actions at different levels could enhance the quality of antenatal care and contribute for favorable pregnancy outcomes, while more researches are structured to clarify the evidences on these relationships.

\section{Competing Interests Statement}

The authors declare that there are no competing or potential conflicts of interest.

\section{Supporting Agencies}

Programa de Pós-graduação em Saúde Pública da Faculdade de Saúde Pública, Universidade de São Paulo; Capes; CNPq. AUXPE-1801/2015-Process: 23038.004624/2015-69. CNPq-Process: 476505/2012-7. CNPq: Process: 141997/2013-3.

\section{References}

Ainamo, J., \& Bay. I. (1975). Problems and proposals for recording gingivitis and plaque. International Dental Journal, 25(4), 229-235. https://doi.org/10.2337/diacare.28.suppl_1.S37

Amar, S., \& Chung, K. M. (1994). Influence of hormonal variation on the periodontium in women. Periodontology 2000, 6, 79-87. https://doi.org/10.1111/j.1600-0757.1994.tb00028.x

Anim-Nyame, N., Gamble, J., Sooranna, S. R., Johnson, M. R., Sullivan, M. H., \& Steer, P. J. (2003). Evidence of impaired microvascular function in pre-eclampsia: A non-invasive study. Clinical Science (London, England: 1979), 104(4), 405-412.

Armitage, G. C. (1999). Development of a classification system for periodontal diseases and conditions. Annals of Periodontology/the American Academy of Periodontology, 4(1), 1-6. https://doi.org/10.1902/annals.1999.4.1.1.

Bastos, M. F., Lima, J. A., Vieira, P. M., Mestnik, M. J., Faveri, M., \& Duarte, P. M. (2008). TNF-alpha and IL-4 levels in generalized aggressive periodontitis subjects. Oral Diseases, 15(1), 82-87. https://doi.org/0.1111/j.1601-0825.2008.01491.x

Batchelor, P. (2014). Is periodontal disease a public health problem? British Dental Journal, 217(8), 405-409. https://doi.org/10.1038/sj.bdj.2014.912 
Blencowe, H., Cousens, S., Oestergaard, M. Z., Chou, D., Moller, A. B., Narwal, R., ... \& Lawn, J. E.. (2012). National, regional, and worldwide estimates of preterm birth rates in the year 2010 with time trends since 1990 for selected countries: a systematic analysis and implications. Lancet, 379(9832), 2162-2172. https://doi.org/10.1016/S0140-6736(12)60820-4

Carrillo-de-Albornoz, A., Figuero, E., Herrera, D., \& Bascones-Martínez, A. (2010). Gingival changes during pregnancy: II. Influence of hormonal variations on the subgingival biofilm. Journal of Clinical Periodontology, 37(3), 230-240. https://doi.org/ 10.1111/j.1600-051X.2009.01516.x

Chapple, I. L. (2014). Time to take periodontitis seriously. BMJ, 10(348), 2645. https://doi.org/10.1136/bmj.g2645

Cohen, D. W., Friedman, L., Shapiro, J., \& Kyle, G. C. (1969). A longitudinal investigation of the periodontal changes during pregnancy. Journal of Periodontology, 40(10), 563-570. https://doi.org/10.1902/jop.1969.40.10.563

Darveau, R. P. (2010). Periodontitis: a polymicrobial disruption of host homeostasis. Nature reviews. Microbiology, 8(7), 481-490. https://doi.org/10.1038/nrmicro2337

Davenport, E. S., Williams, C. E., Sterne, J. A., Sivapathasundram, V., Feme, S., \& Curtis, M. (1998). The east London study of maternal chronic periodontal disease and preterm low birth weight infants: study design and prevalence data. Annals of Periodontology/the American Academy of Periodontology, 3(1), 213-221. http://doi.org/10.1902/annals.1998.3.1.213

Ferris, G. M. (1993). Alteration in female sex hormones: Their effect on oral tissues and dental treatment. Compendium (Newtown, Pa.), 14(12), 1558.

Frazão, P. (2009). 20 years of experience with the brazilian unified national health system: strides and challenges $\begin{array}{lllll}\text { for oral health, Cadernos de Saude } & \end{array}$ http://dx.doi.org/10.1590/S0102-311X2009000400001

Goldenberg, R. L., Culhane, J. F., Iams, J. D., \& Romero, R. (2008). Epidemiology and causes of preterm birth. Lancet, 371(9606), 75-84. https://doi.org/10.1016/S0140-6736(08)60074-4

Huck, O., Tenenbaum, H., \& Davideau, J. L. L. (2011). Relationship between periodontal diseases and preterm birth: recent epidemiological and biological data. Journal of Pregnancy, 2011, 164654. http://dx.doi.org/10.1155/2011/164654

Jeffcoat, M. K., Geurs, N. C., Reddy, M. S., Cliver, S. P., Goldenberg, R. L., \& Hauth, J. C. (2001). Periodontal infection and preterm birth: results of a prospective study. Journal of the American Dental Association, 132(7), 875-880. https://doi.org/ 10.14219/jada.archive.2001.0299

Katz, J., Lee, A. C., Kozuki, N., Lawn, J. E., Cousens, S., Blencowe, H., ... Black, R. E. et al. (2013). Mortality risk in preterm and small-for-gestational-age infants in low-income and middle-income countries: A pooled country analysis. Lancet, 382(9890), 417-425. http://doi.org/ 10.1016/S0140-6736(13)60993-9

Kawar, N., \& Alrayyes, S. (2011). Periodontitis in pregnancy: the risk of preterm labor and low birth weight. Disease-a-month: DM, 57(4), 192-202. http://dx.doi.org/10.1016/j.disamonth.2011.03.005

Keelan, J. A., Blumenstein, M., Helliwell, R. J., Sato, T. A., Marvin, K. W., \& Michell, M. D. (2003). Cytokines, prostaglandins and parturition--a review. Placenta, 24(Suppl A), S33-46. https://doi.org/10.1053/plac.2002.0948.

Kloetzel, M. K., Huebner, C. E., Milgrom, P., Littell, C. T., \& Eggertsson, H. (2012). Oral health in pregnancy: educational needs of dental professionals and office staff. Journal of Public Health Dentistry, 72(4), 279-286. https://doi.org/10.1111/j.1752-7325.2012.00333.x

Kolenbrander, P. E., Palmer, R. J., Periasamy, S., \& Jakubovics, N. S. (2010). Oral multispecies biofilm development and the key role of cell-cell distance. Nature Reviews Microbiology, 8(7), 471-480. https://doi.org/ 0.1038/nrmicro2381

Kramer, M. S., Kahn, S. R., Platt, R. W., Genest, J., Chen, M. F., Goulet, L. ... \& Thorsen, P. (2009). Mid-trimester maternal plasma cytokines and CRP as predictors of spontaneous preterm birth. Cytokine, 49(1), 10-14. https://doi.org/ 10.1016/j.cyto.2009.08.014

Kumar, A., Begum, N., Prasad, S., Lamba, A. K., Verma, M., Agarwal, S., \& Sharma, S. (2014). Role of cytokines in development of pre-eclampsia associated with periodontal disease - Cohort Study. Journal of Clinical Periodontology, 41(4), 357-365. https://doi.org/ 10.1016/j.cyto.2009.08.014 
Lawn, J. E., Wilczynska-Ketende, K., \& Cousens, S. N. (2006). Estimating the causes of 4 million neonatal deaths in the year 2000. International Journal of Epidemiology, 35(3), 706-718. https://doi.org/10.1093/ije/dyl043

Lima Oliveira, A. P., Faveri, M., Gursky, L. C., Mestnik, M. J., Feres, M., Hafajee, A. D., Socransky, S. S., \& Teles, R. P. (2012). Effects of periodontal therapy on GCF cytokines in generalized aggressive periodontitis subjects. Journal of Clinical Periodontology, 39(3), 295-302. https://doi.org/10.1111/j.1600-051X.2011.01817.x

Lin, D., Smith, M. A., Champagne, C., Elter, J., Beck, J., \& Offenbacher, S. (2003). Porphyromonas gingivalis infection during pregnancy increases maternal tumor necrosis factor alpha, suppresses maternal interleukin-10, and enhances fetal growth restriction and resorption in mice. Infection and Immunity, 71(9), 5156-5162. https://doi.org/ 10.1128/IAI.71.9.5156-5162.2003

Loe, H., Theilade, E., \& Jensen, S. B. (1964). Experimental gingivitis in man. The Journal of Periodontology, 36, 177-187. https://doi.org/10.1902/jop.1965.36.3.177

Macedo, J. F., Ribeiro, R. A., Machado, F. C., Assis, N. M., Alves R. T., Oliveira, A. S., \& Ribeiro, L. C. (2014). Periodontal disease and oral health-related behavior as factors associated with preterm birth: a case-control study in south-eastern Brazil. Journal of Periodontal Research, 49(4), 458-464. https://doi.org/10.1111/jre.12124

Madianos, P. N., Bobetsis, Y. A., \& Offenbacher, S. (2013). Adverse pregnancy outcomes (APOs) and periodontal disease: pathogenic mechanisms. Journal of Clinical Periodontology, 40(14), 80. https://doi.org/10.1111/jcpe.12082

Madianos, P. N., Lieff, S., Murtha, A. P., Boggess, K. A., Auten-Jr, R. L., Beck, J, D., \& Offenbacher, S. (2001). Maternal periodontitis and prematurity. Part II: Maternal infection and fetal exposure. Annals of Periodontology / the American Academy of Periodontology, 6(1), 175-182. https://doi.org/10.1902/annals.2001.6.1.175

Mawardi, H. H., Elbadawi, L. S., \& Sonis, S. T. (2015). Current understanding of the relationship between periodontal and systemic diseases. Saudi Medical Journal, 36(2), 150-158. https://doi.org/10.15537/smj.2015.2.9424

Michalowicz, B. S., DiAngelis, A. J., Novak, M. J., Buchanan, W, Papapanou, P. N., Mitchell, D. A., ... \& Rogers, T. B. (2008). Examining the safety of dental treatment in pregnant women. Journal of the American Dental Association, 139(6), 685-695. http://dx.doi.org/10.14219/jada.archive.2008.0250

Muwazi, L., Rwenyonyi, C. M., Nkamba, M., Kutesa, A., Kagawa, M., Mugyenyi, G. ... \& Okullo, I. (2013). Periodontal conditions, low birth weight and preterm birth among postpartum mothers in two tertiary health facilities in Uganda. Biomed Central Oral Health, 14, 42. http://doi.org/10.1186/1472-6831-14-42

Nibali, L., Farias, B. C., Vajgel, A., Tu, Y. K., \& Donos, N. (2013). Tooth loss in aggressive periodontitis: a systematic review. Journal of Dental Research, 92(10), 868-875. https://doi.org/10.1177/0022034513501878

Offenbacher, S. (2004). Maternal periodontal infections, prematurity, and growth restriction. Clinical Obstetrics and Gynecology, 47(4), 808.

Offenbacher, S., Boggess, K. A, Murtha, A. P, Jared, H. L., Lieff, S., McKaig, R. G. ... \& Beck, J. (2005). Progressive periodontal disease and risk of very preterm delivery. Obstetrics and Gynecology, 107(1), 29-36. https://doi.org/10.1097/01.AOG.0000190212.87012.96

Offenbacher, S., Jared, H. L., O'Reilly, P. G., Wells, S. R., Salvi, G. E., Lawrence, H. P. .. \& Beck, J. D. (1998). Potential pathogenic mechanisms of periodontitis associated pregnancy complications. Annals of periodontology / the American Academy of Periodontology, 3(1), 233-250. http://doi.org/10.1902/annals.1998.3.1.233

Offenbacher, S., Lieff, S., Boggess, K. A., Murtha, A. P., Madianos, P. N., Champagne, C. M. E. ... \& Beck, J. D. (2001). Maternal periodontitis and prematurity. Part I: Obstetric outcome of prematurity and growth restriction. Annals of periodontology/the American Academy of Periodontology, 6(1), 164-174. https://doi.org/10.1902/annals.2001.6.1.164

Papapanou, P. N. (2015). Systemic effects of periodontitis: lessons learned from research on atherosclerotic vascular disease and adverse pregnancy outcomes. International Dental Journal, 65, 283-291. https://doi.org/10.1111/idj.12185.

Petersen, P. E., \& Ogawa, H. (2005). Strengthening the prevention of periodontal disease: the WHO approach. Journal of Periodontology, 76(12), 2187-2193. https://doi.org/10.1902/jop.2005.76.12.2187 
Petrou, S., Abangma, G., Johnson, S., Wolke, D., \& Marlow, N. (2008). Costs and health utilities associated with extremely preterm birth: evidence from the EPICure study. Value in Health: the Journal of the International Society for Pharmacoeconomics and Outcomes Research, 12(8), 1124-1134. https://doi.org/10.1111/j.1524-4733.2009.00580.x

Pihlstrom, B. L., Michalowicz, B.S., \& Johnson, N. W. (2005). Periodontal diseases. Lancet, 366(9499), 1809-1820. https://doi.org/10.1016/S0140-6736(05)67728-8

Raber-Durlacher, J. E., Leene, W., Palmer-Bouva, C. C., Raber, J., \& Abraham-Inpijn, L. (1993). Experimental gingivitis during pregnancy and post-partum: immunohistochemical aspects. Journal of Periodontology, 64(3), 211-218. https://doi.org/10.1111/j.1600-051X.1994.tb01172.x

Saigal, S., \& Doyle, L. W. (2008). An overview of mortality and sequelae of preterm birth from infancy to adulthood. Lancet, 371(9608), 261-269. https://doi.org/10.1016/S0140-6736(08)60136-1

Schwab, L. G., Moyses, T. S., Franca, B. H. S., Werneck, R. I., Frank, E., \& Moysés, S. J. (2014). Chronic conditions policies: oral health, a felt absence. International Dental Journal, 64(2), 83-88. https://doi.org/10.1111/idj.12066

Sert, T., Kirzioglu, F. Y., Fentoglu, O., Aylak, F., \& Mungan, T. (2011). Serum placental growth factor, vascular endothelial growth factor, soluble vascular endothelial growth factor receptor-1 and -2 levels in periodontal disease, and adverse pregnancy outcomes. Journal of Periodontology, 82(12), 1735-1748. https://doi.org/10.1902/jop.2011.100740

Sooriyamoorthy, M., \& Gower, D. B. (1989). Hormonal influences on gingival tissue: relationship to periodontal $\begin{array}{lllll}\text { disease. Journal of Clinical Periodontology, } & \text { 16(4), }\end{array}$ https://doi.org/10.1111/j.1600-051X.1989.tb01642.x.

Steinberg, B. J., Hilton, I. V., Iida, H., Iada, H., \& Samelson, R. (2013). Oral health and dental care during pregnancy. Dental Clinics of North America, 57(2), 195-210. https://doi.org/10.1016/j.cden.2013.01.002

Takeuchi, N., Ekuni, D., Irie, K., Furuta, M., Tomofuji, T., Morita, M., \& Watanabe, T. (2013). Relationship between periodontal inflammation and fetal growth in pregnant women: a cross-sectional study. Archives of Gynecology and Obstetrics, 287(5), 951-957. https://doi.org/10.1155/2011/164654

Tarannum, F., Faizuddin, M., \& Madaiah, H. (2011). Gingival crevicular fluid prostaglandin E2 level as a predictor of preterm low birth weight: a pilot investigation. Journal of Oral Science, 53(3), 293-300. https://doi.org/10.2334/josnusd.53.293

Thomson, W. M., Sheiham, A., \& Spencer, A. J. (2012). Sociobehavioral aspects of periodontal disease. Periodontol 2000, 60(1), 54-63. https://doi.org/10.1111/j.1600-0757.2011.00405.x

Thousand, Oaks. (2012). Pathogenic mechanisms linking periodontal diseases with adverse pregnancy outcomes. Reproductive Sciences (Calif.), 19(6), 633-641. https://doi/10.1177/1933719111432871.

Tonetti, M.S., D'Aiuto, F., Nibali, L., Donald, A., Storry, C., Parkar, M., ... \& Deanfield, J. (2007). Treatment of periodontitis and endothelial function. The New England Journal of Medicine, 356(9), 911-920. https://doi.org/10.1056/NEJMoa063186

Uppal, A, Uppal, S., Pinto, A., Dutta, M., Shrivatsa, S., Dandolu, V., \& Mupparapu, M. (2010). The effectiveness of periodontal disease treatment during pregnancy in reducing the risk of experiencing preterm birth and low birth weight: a meta-analysis. Journal of the American Dental Association, 141(12), 1423-1434. https://doi.org/10.14219/jada.archive.2010.0104

Vamos, C. A., Walsh, M. L., Thompson, E., Daley, E. M., Detman, L., \& DeBate, R. (2015). Oral-systemic health during pregnancy: exploring prenatal and oral health providers' information, motivation and behavioral skills. Maternal and Child Health Journal, 19(6), 1263-75. https://doi:10.1007/s10995-014-1632-7

World Health Organization (WHO). (2016). Preterm birth. Retrieved June 14, 2017 from https://www.who.int/mediacentre/factsheets/fs363/en/

World Health Organization (WHO). (2008). The world health report 2008: primary health care (now more than ever). Disponível em: < https://www.who.int/whr/2008/en/>. Acesso em 14 de junho de 2017.

Zachariasen, R. D. (1992). The effect of elevated ovarian hormones on periodontal health: oral contraceptives and pregnancy. Women \& Health, 20(2), 21-30. https://doi.org/10.1300/J013v20n02_02

Zi, M. Y., Longo, PL, Bueno-Silva, B., \& Mayer, M. P. (2013). Mechanisms involved in the association between 
periodontitis and complications in pregnancy. Frontiers in Public Health, 29(2), 290. https://doi.org/10.3389/fpubh.2014.00290

\section{Copyrights}

Copyright for this article is retained by the author(s), with first publication rights granted to the journal.

This is an open-access article distributed under the terms and conditions of the Creative Commons Attribution license (http://creativecommons.org/licenses/by/4.0/). 